adopted a motion by General Perrier to request the general secretary to convey the congratulations of the Union by sending a copy of the minutes to the secretary of the United States Department of Commerce.

In connection with the work of the Reduced Geodetic Association and Dr Muller's letter, as given in the President's report, Mr Bowie moved that the general secretary of the Union be requested to convey to Dr F. Baeschlin at Zollikon, the thanks of the Committee for the valuable work done by it in completing and publishing the reductions for the period $I 9 I 2 \cdot 0$ to I 922.7 . Seconded and carried unanimously.

\title{
Commission 20. (Minor Planets, Comets And Satellites.)
}

President: Prof. A. O. Leuschner.

SECRETARY: Mr H. E. Wood.

The President extended a welcome to Dr Kopff who was present at the meeting.

No formal report was presented to the Commission for adoption, but on the suggestion of the President the meeting discussed seriatim various proposals which had been brought forward by members of the Commission and which had been circulated.

(I) A proposal, emanating from Belgium, had been made for an improvement of the present plan for the distribution of observations and computations relating to minor planets and comets, with special reference to those which depart considerably from their ephemerides. The President expressed his opinion that the present arrangements, which were following a natural plan of evolution, were quite satisfactory and should be allowed to continue for some time. Dr Kopff agreed that further organization was at present unnecessary. No motion was taken on this proposal.

(2) With reference to the suggestion that there should be a central bureau (or bureaus) under the auspices of the Union to supervise any accepted plan for the co-ordination of observations and computations relating to minor planets and comets, the President said that the discussion on proposal (I) indicated that this was not necessary. He considered that a rigid organization was not desirable unless there was really a definite need for such. He referred to the spontaneous growth of activities covering present needs and mentioned as an example the work being done in the case of comets by Dr Crommelin and members of the British Astronomical Association. He suggested, however, that the formation of a small sub-committee of Commission 20, which would concern itself with the collection of information as to the work being done by various computers bearing on the return of periodic comets, would be of value. Such a committee would keep in touch with individuals interested in such work and would assist in preventing any unnecessary overlapping of effort and the possible neglect of any periodic comet. A motion was carried to the effect that the President of Commission 20 for the ensuing period should be instructed to establish such a committee from the members of the Commission.

(3) It was announced that systematic investigations of the orbits of the recently discovered objects designated as minor planets: Reinmuth r932 HA and Delporte I932 EA, were being undertaken at the Astronomisches Rechen-Institut.

(4) The proposals for the establishment of a central bureau (or bureaus) within the Union not having been accepted, the question of financial aid did not arise. 
(5) The question of the adoption of a Standard Equinox, to which observations should be referred, was discussed at very considerable length. The President, in introducing the subject, referred to the fact that Dr L. J. Comrie had, some years ago, proposed the adoption of $195^{\circ} \circ$ as a standard Equinox of reference and that the Nautical Almanac had already adopted this Equinox and had prepared and published auxiliary tables for the reduction of observations and the computation of orbits with reference to special perturbations, using this Equinox. On the other hand, Dr E. C. Bower of the Lick Observatory advocated the adoption of I900.o as a standard Equinox. The Astronomisches Rechen-Institut, in preparing the ephemerides of minor planets, was now using the Equinox of I925.0 but would adopt the $195^{\circ} 0$ Equinox in I938 and had made preparations for such change.

Dr Comrie reviewed the history of this question. He said that the function of the Nautical Almanac offices was to give astronomers the information that the astronomers themselves desired but it did appear that there were some matters in which the astronomers desired a lead. In the year I926 he had suggested the adoption of $I 950^{\circ} 0$ as a standard Equinox. Having in mind the general conservatism of astronomers and the length of time required to attain a general agreement, he considered that it was then too late to adopt I900.0 as a standard Equinox and that provision should be made for the adoption of the Equinox of $195^{\circ} 0$, which might be used until I980.

At the meeting of the International Astronomical Union at Leiden in 1928 the adoption of $195^{\circ} 0$ as a standard Equinox was agreed to and the Nautical Almanac office then proceeded to compute and publish co-ordinates referred to this Equinox. A number of important star catalogues, referred to the Equinox of $195^{\circ} 0$, were now in preparation and would shortly be in general use.

The principal argument in favour of the proposal by Bower that the Equinox of I900.0 should continue to be used as the standard is that the majority of observations of minor planets and comets made at the present time depend upon astrographic star places for I900.0 and that no provision for the application of precession had been made in the astrographic catalogues. The value of this argument at the present time was admitted, but it would soon disappear with the publication of new catalogues now in preparation.

The President referred to the customary practice of observers of minor planets and comets in referring their observations, intended for use in the computation of preliminary orbits, to the Equinox of the beginning of the year. In the transmission of astronomical telegrams this Equinox was also used. Dr Kopff also agreed that it was not desirable to change this procedure.

The President suggested that Commission 20 should do nothing to interfere with the steps now being taken to adopt I950.0 as a standard Equinox, but, from the practical point of view, should support the continuance of the use of the Equinox of I900.0 until the new catalogues for I950.0 are available and should ask for the assistance of the various Nautical Almanacs in supplying auxiliary tables for I900.0 as well as for $195^{\circ} \mathrm{O}$.

The following motion was adopted, moved by Prof. van Biesbroeck, seconded by Dr B. H. Dawson: " that the President of Commission 20 be requested to take such steps as he may deem necessary or advisable to ascertain the general opinion of computers and observers in regard to the co-operation of the Nautical Almanac offices in furnishing data for the Equinox of I900*0."

(6) On the suggestion forwarded by M. Giaccobini it was agreed that in the 
publication of the results of visual observations of minor planets and comets, the quantities $\Delta \alpha, \Delta \delta$, i.e. object -comparison star, should be given as apparent $\Delta \alpha$ observed, $\Delta \delta$ observed, unless in addition to differential refraction the differential corrections for precession, nutation and aberration had been applied. In practice many observers applied $\Delta \alpha, \Delta \delta$ directly to the mean position of the comparison star, thus leading to the assumption that the observed differences had been suitably corrected for the change of Equinox, a correction which might sometimes be sensible.

(7) The Commission reaffirmed its adherence to the new convention for the dates to be used in the preparation of ephemerides of minor planets and comets, and desired to see greater attention paid to this. It was suggested that all members of the Commission should assist in spreading knowledge of this convention and that the President of the Commission should write to individual astronomers who did not follow it.

The President made the suggestion that in the computation of cometary ephemerides, the first date of a new ephemeris should, whenever possible, be made to coincide with the last date of any running-out ephemeris or the two ephemerides should even be made to overlap for a short period.

(8) It was suggested that in the preliminary publication of the observations of comets, a comparison between the observations and a current ephemeris might be given; as is done in the Beobachtungs-Zirkulare issued by the Astronomisches Rechen-Institut in the case of minor planets.

(9) It was suggested that the code for astronomical telegrams might receive some slight modification which would permit the inclusion of some information of a descriptive nature. Observers of comets might wish to receive (or transmit) information relating to the character of the comet, e.g. possession of a tail, nucleus, etc.; or even to indicate by code the order of accuracy of an observation. On the other hand the Central Bureau for Astronomical Telegrams did not desire any change which might increase the expense of the telegraphic service or add to the possibility of errors in the coding and decoding of astronomical telegrams. As most of the members of Commission 6 were present during this discussion, it was considered that this question would receive due attention in that Commission and it was accordingly resolved "that Commission 6 be requested to give further consideration to the proposal that astronomical telegrams might contain some information of a descriptive nature."

(I0) Dr Kopff suggested that all observers in communicating their observations of planets and comets should state whether such observations were considered to be final and definitive or were to be subject to some later revision. He also made the request that all investigators concerned with minor planets should communicate fully with the Astronomisches Rechen-Institut, as that Institute is well acquainted with all work that has been done or is in progress on minor planets, and such communication might prevent the unnecessary duplication of effort and possibly also the overlooking of work of importance.

(II) Prof. B. V. Numerov forwarded to the Commission a suggestion to inaugurate an international project to observe certain minor planets with the object of determining systematic errors of fundamental declinations of stars. A similar suggestion is mentioned in Sir Frank Dyson's report to Commission 8.

It was recommended that Prof. Numerov should be asked to publish his plan in detail prior to formal consideration. 
Prof. K. Hirayama reported progress on his researches of the asteroid families. Out of the II77 asteroids listed in Kleine Planeten for 1932, he could select 34 asteroids belonging to the Themis family, 34 to the Eos family, 22 to the Coronis family, $x 6$ to the Maria family and 78 to the Flora family. The total number of the asteroids belonging to the five principal families are now I84 or 15.6 per cent. of the total number. This percentage was $14^{\circ} \mathrm{O}$ in the first paper written in 1923 and 14.9 in the second paper written in 1927 . This increase of percentage seems to indicate that smaller asteroids are more liable to belong to the families.

He also drew attention to the Hilda-type planets, which are Io in number. The limits of the mean motions of these planets are $447^{\prime \prime}-460^{\prime \prime}$ and the critical argument, i.e. "(mean longitude of asteroid) - (mean longitude of Jupiter) + longitude of perihelion of asteroid," is limited to $294^{\circ}-59^{\circ}$, i.e. to an interval of $125^{\circ}$. He recommended we should use the term "Hilda group" for these planets, in the same sense as we refer to the "Trojan group."

E. Delporte reported that he had re-found 594 Mireille, which had not been observed since I9I9, and attributed success in this case to the use of Metcalf's method.

F. Kepiński has published: The return of the periodic comet Kopff Igo6e (Varsovie, I932); The motion of the periodic comet Kopff I906e, Part I-presented to the Académie Polonaise des Sciences. With the help of this Ephemeris the comet was re-found on 1932 May 25, at Cordoba.

M. Kamiensski has continued his investigations of the motion of Comet Wolf (I). Fifty normal places derived from I 888 observations covering 6 returns during the period r884-I9I9 can now be represented with a mean error of $\pm I^{\prime \prime} \cdot 77$ on the assumption that the mean daily motion of the comet is diminishing by the amount of $\mathrm{O}^{\prime \prime} \cdot 00000042$ in one day. The results are published in Publications of the Astronomical Observatory of Warsaw, vols. IV, v, vr, and a further article "Ueber die Bewegung des Kometen Wolf (I) in dem Zeitraume I884-I9I9" has been awaiting publication since April I93I.

Attention was also drawn to the following papers which have recently appeared:

G. Fayet: "Les Petites Planètes" (Ann. du Bureau des Longitudes, I932);

"L'Etude des Excentricités des Orbites Cométaires"; "Tables de Petites Planètes."

P. E. de la Villemarque, S.J.: "(II3) Amalthea" (Annales de Zó-Sé, Tome Xvir, Fasc. v).

D. Brouwer: "Theory and Tables of the Motion of (588)."

E. W. Brown and D. Brouwer: "Tables for use in the development of the disturbing function."

Reference was also made to the forthcoming Research Surveys of the Minor Planets to be published as a Lick Observatory publication in two volumes and to a projected catalogue of general cometary data by Bobrovnikoff.

\section{Commission 22. (ÉToIles FILANTEs.)}

President: Prof. Olivier.

SeCretary: M. F. De Roy.

The Rev. T. E. R. Phillips submitted a proposal from Commission I6, suggesting that Commission 22 should take from them the subject of comets. After some discussion, in which it was pointed out that, on practical grounds, the methods of observation should outweigh any theoretical considerations in the matter, the 